\title{
Morphological Characterization of Chicken Feather Rachis, Neem Sawdust, and High Density Polyethylene (HDPE) Reinforced Composite Material
}

\author{
Gayatri Uppalapati $^{1^{*}}$, Srinivasarao Gunji ${ }^{2}$, Ramakrishna Malkapuram ${ }^{3}$ \\ ${ }^{1}$ Mechanical Engineering Department, Acharya Nagarjuna University, Nagarjuna Nagar 522508, India \\ ${ }^{2}$ Mechanical Engineering Department, RVR\&JC College of Engineering, Chandramoulipuram 507169, India \\ ${ }^{3}$ Mechanical Engineering Department, VFSTR, Vadlamudi 522213, India
}

Corresponding Author Email: ugayatri310@gmail.com

https://doi.org/10.18280/acsm.440605

Received: 4 May 2020

Accepted: 12 November 2020

\section{Keywords:}

FESEM, XRD, HDPE $(H)$ Granules, Chicken

Feather (CF), Saw Dust (SD)

\begin{abstract}
In this paper research was expanded on waste that can be recycled. There are so many different types of waste products available in our country that would ruin the environment. Three different products are considered to reduce some of the problems among them two are fibers and the other is polyethylene. Chicken feather rachis and Neem sawdust are the two different fibers and the reinforced material is high density polyethylene (HDPE). These materials are made as seven different compositions to find the ability of the sample in different characterizations. The seven compositions are $80 \mathrm{H}$ 10CF-10SD, 80H-5CF-15SD, 80H-15CF-5SD, 80H-20CF, 70H-30CF, 70H-30SD, 80H20SD, and these compositions are made in CIPET, Hyderabad by using single screw extruder\& strand pelletizer. These granules are prepared with the help of Injection moulding, the samples are examined by various testing to prove the ability, strength, structure of materials in individual, and combination forms. The testing conducted for the samples is that the Morphology of the sample was characterized using FESEM, XRD. It is examined that the ratios are light weight with high strength by using the testings and it gives perfect images without any cracks on the surface and no more defects among these ratios.
\end{abstract}

\section{INTRODUCTION}

Today, individuals are becoming more conscious of the ecological issues and their problems that are spoiling against the material than at any other time. Legislative strategies are compelling enterprises and organizations to discover sustainable assets to supplant conventional ones [1]. This has driven us ever nearer to regular resources and their use. Be that as it may, while the interest for environmental mindful applications is expanding, the worry about the shortage and availability of natural resources is increased. Simultaneously, the development of population, rising urbanization, and better expectations of living create increasingly more waste constantly. This waste likewise incorporates bio-based materials that could be additionally used.

This is the reason why scientists and industries are concentrating on discovering better approaches to use biobased waste streams to create value-added inexhaustible and feasible product solutions for supplanting traditional ones. While considering the most all-inclusive plentiful, exceptional and cheap waste streams which could be used for esteem include applications, one can't pass the poultry. The waste in the poultry industry comprises of quills, inward organs, blood, bones, skin, feet, and leftover meat. Out of these co products, particularly, poultry quills [2] have pulled in intrigue. It has been anticipated that in 2017, just the broiler meat creation will be 89.5 million tons around the world (USDA, 2017). On the off chance that it is, at that point accepted that the poultry business squander covers $30 \%$ of its all-out weight and chicken feather establish around $10 \%$ of chicken's [3, 4] weight, the chicken quill waste can be thought to be 12 million tons around the world. At the same time sawdust also a major problem in our environment, because of furniture in home doors windows and so many things we make with trees, without trees we are losing so much at the same time this dust will not soluble. So, we have to stop cutting trees and re-use the dust in other purpose which will not spoil nature. So, two different fibers are considered in this work.

The Five varieties of composite specimens are considered to study the progression of fiber-matrix adhesion using a hand layup method [5]. The Ampeg 21 epoxy resin was used as a matrix for glass fiber-epoxy resin and E-Glass fiber was used for matrix reinforcement. Here Morphology and the XRD methods are examined. In the morphology the fractured structure and in EDS the elemental composition observed. In the XRD process the results show the Bragg's angle $\theta=20.6^{\circ}$, the crystalline structure is silica in the composite. So, this composite is projected that it gives, better dimensional stability and high-performance structural applications.

The composite materials made up of natural resources are more frequently used, as they are low-cost and less weight which was emphasized in this work [6]. The study of polymer composite of polyvinyl chloride (PVC) using palm fibers at different loadings such as $10 \%$ and $30 \%$ by weight. Using a chemical modification of date palm fibers between matrixfiller interfaces, considering two types of testing's alkali, acetylation. By examining the ratios using morphological, thermal, and mechanical and Water absorption properties of 
composites give fewer properties and water absorption.

The aeronautic trade centered around the framework TiTiAl-BuC, which has decent relations between the properties and microstructure, as far as the procedure parameters of the titanium and matrix composite [7]. The powder metallurgy method was utilized the TMCs which can manufacture the inductive hot squeezing, it offers the adaptability and flexibility. The short handling time utilized ( $5 \mathrm{~min})$ was set to test the temperature as a central point to impact in the secondary relations. Concerning preparing conditions, the higher the weight, the more substance of $\mathrm{TiB}$ and $\mathrm{TiC}$ at comparative handling temperature, paying little mind to the starting powder.

The composite materials which are based on Polytetrafluoroethylene studies on the X-Ray structure of amorphous-crystalline which were performed at hightemperature heating [8]. The thermal stability limits of the structures of composites were determined and the crystalline and amorphous components of the composite matrices of temperature dependencies of the parameters were determined and examined.

Right now, it was extricated from the expendable chicken feather utilizing l-cysteine as a lessening agent [9]. At that point, it was re-disintegrated in the sodium carbonate-sodium bicarbonate support, and the pure keratin membrane and fiber were manufactured by specialist cutting edge throwing procedure and wet spinning process, individually. SEM, FTIR spectroscopy, XRD, and TGA were utilized to describe the chemical and physical properties of coming about powder, membrane, and fiber.

$\mathrm{SnCl}_{4} /$ nano-sawdust was set up as a starch-based impetus containing of tin bearing cellulose units [10]. The impetus was described by XRD, FT-IR, FESEM, and EDS. The impetus was applied effectively as a promptly accessible, reasonable, biodegradable, and naturally favorable heterogeneous biobased strong corrosive for the one-pot amalgamation of 2subbed benzimidazoles and benzothiazoles.

The characterization and preparation of magnetitecarboxymethyl cellulose nano-composite (M-CMC) material is depicted [11]. Magnetite nanoparticles were incorporated by an altered co-precipitation strategy utilizing ferrous chloride tetrahydrate and ferric chloride hexahydrate in ammonium hydroxide arrangement. The biocompatible $\mathrm{Fe}_{3} \mathrm{O}_{4}$ carboxymethyl cellulose nanocomposite particles acquired from the normal CMC polymers have a potential scope of use in the biomedical field.

The seven different ratios have been prepared and three variety of testings such as FESEM, EDAX and XRD performed on all the ratios to find the micro structure and compositions in this work.

\section{MATERIALS AND METHODS}

\subsection{Considered materials}

In this work one matrix and two fibers are used. Those are HDPE Granules as a matrix, neem sawdust, and chicken feather rachis as fibers. In HDPE Granules there are so many different types of grades available, out of which HD50MA180 is considered as matrix. This grade is useful for high strength injection molding products and for thin wall molded products its melt flow index is good compared with other grades of granules, its mechanical properties, and thermal properties also very good. So, by comparing with other grades, this is the best one to improve the strength and flexibility this grade has to be considered. The only matrix cannot make the sample strong and flexible so for making stronger, a matrix needs fiber to become a composite material and here it is having two different types of fibers used which are reused to become a hybrid composite material

Neem sawdust [12] is one of the fibre used which is collected from the timber mill when the neem logs are cutting down, that collected sawdust is not having some size and shape it is just a particle mixing all the parts of the tree except leaves. These particles are sent to a mixture machine to get a fine powder. After that let that powder dry in the oven at room temperature for 2-3 hrs. So that the powder gets completely dry having no moisture content in that neem sawdust. It is one of the flexible, strong fiber, which is having low-cost and more available for low-class people.

The second fibre considered is chicken feather rachis which is not used till now. It was collected from any farm and washed with hot water to remove the dust particles on that feather. After they are dried using a dryer or keep them in the oven for 3 hrs to make them completely dry. Later the outer parts of a feather are removed and remains only the middle part of the feather which is called the rachis. By considering the low-cost and high strength this is considered as one of the fibers.

\subsection{Testing methods}

SEM was designed about 50 years prior, SEM [13, 14] is currently a full-grown strategy and is applied broadly in numerous logical applications. SEM is an amazing technique in the assessment of materials metallurgy. The FESEM [15, 16] (Field Emission Scanning Electron Microscope) is the latest update of SEM. In this FESEM the magnification of 10X to $300,000 \mathrm{X}$ with virtually unlimited depth of field, produce clearer less electrostatically distorted images with spatial resolution down to 1.5 nanometers three to six times better than SEM. This FESEM has done in PSG, Coimbatore, make ZEISS (USA), model: SIGMA with GEMINI COLUMN, Resolution $1.5 \mathrm{~mm}$, in-lens detector, SE2 detector, BSD detector. In FESEM for each sample five images have considered at 20um, 10um, 2um, width WD=10mm, $\mathrm{EHT}=10.00 \mathrm{kv}$, signal A2 $=\mathrm{SE} 2$ magnification are $500 \mathrm{X}$, $1.00 \mathrm{KX}, 2.50 \mathrm{KX}, 5.00 \mathrm{KX}, 10.00 \mathrm{KX}$.

EDAX used to recognize the elemental material composition. The information produced by $\operatorname{EDX}[17,18]$ analysis comprises of spectra indicating peaks compared to the elements making up the genuine composition of the test is analyzed. This detector is utilized to isolate the XRD characteristics of various elements into a vitality range, and EDS framework programming is utilized to investigate the energy spectrum to decide the wealth of explicit elements.

To know the energy-dispersive XRD analysis, EDXA is an expository procedure utilized for the essential investigation or chemical portrayal of a sample that depends on the connection between the sample and x-beam show. At the point when associated with SEM, EDXA can quickly perform a basic investigation on elemental analysis of various territories at the sample which can give data in regards to the sample composition. This is done in PSG, Coimbatore, make: BRUKER(GERMAN), model: Nano x flash detector, EDAX (elemental analysis), point scan, line scan, area scan, and elemental mapping.

$\mathrm{XRD}$ is a quick diagnostic procedure essentially utilized for 
face identification of a crystalline material and can give data on unit cell measurements.

This test is done in the Vignan University CoExAmmpc research lab on the machine Rigaku Miniflex 600, Rigaku Corporation, Japan. In XRD [19, 20] the scan range is from $3.0000-90.0000 \mathrm{deg}$, the scan speed is $10.0000 \mathrm{deg} / \mathrm{min}$, scan mode CONTINUOUS, scan step is $0.0200 \mathrm{deg}$, scan axis is theta /2-Theta, the incident parallel slit is $5.0 \mathrm{deg}$, the incident slit is $1.250 \mathrm{deg}$, length limiting slit is $10.0 \mathrm{~mm}$, the filter is $\mathrm{K}$ beta(x1), receiving parallel slit is $5.0 \mathrm{deg}, \mathrm{X}$-Ray is $40 \mathrm{KV}, 15$ $\mathrm{mA}$, the wavelength is cuka/1.541862A, Goniometer is Miniflex 300/600, the detector is sc-70, the element properties found in these samples are carbon and oxygen. In this the above matter is common for all the samples. We have to take the Theta/2-Theta(deg) with intensity.

\section{PREPARATION OF SAMPLE RATIO}

The seven different ratios have been prepared by two types of machines they are screw extruder machine and injection moulding machine to get the granules from the samples. The ratios prepared are $80 \mathrm{H}: 10 \mathrm{CF}: 10 \mathrm{SD} ; 80 \mathrm{H}: 5 \mathrm{CF}: 15 \mathrm{SD} ; 80 \mathrm{H}$ : 15CF:5SD; 80H: 20CF; 70H: 30CF; 80H: 20SD and 70H: 30SD. In screw extruder one by one ratio is pouring by preheating at temperature $170^{\circ} \mathrm{C}-120^{\circ} \mathrm{C}$ and pour the material into the melt. Then wire shape material will come out from the die and it directly dips into the water which keeps the side of that machine. The melted material comes out from the machine will fell into that water to get cool in a fraction of seconds and by using a cutter machine, it will cut the sample wires in a granule shape and that will be collected in a bag to store. For all the ratios the process is the same, after collecting the sample, without forgetting the label name.

The next one is the injection moulding process, the granules used are made from the screw extruder machine. In the machine pour the granules that granules will melt in a moulding machine to occupy the shaper or die of the mould to get that shape we remove the sample from the mould to get the desired shape for that samples we conduct the following testing's they are FESEM, EXAD, and XRD.

\section{RESULTS AND DISCUSSION}

The composite material which is prepared with different ratios are subjected to examine the morphology characterization using FESEM, EDAX, and XRD.

\subsection{FESEM (Field Emission Scanning Electron Microscope) results}

The FESEM results with composition $80 \mathrm{H}$ : 15CF:5SD are as given in Figure 1.

In the sample $80 \mathrm{H}: 15 \mathrm{CF}: 5 \mathrm{SD}$ there are no cracks found but the upper surface is so smooth when we increase the magnification irregular surfaces are having more up and downs.

The FESEM results with composition $80 \mathrm{H}$ : 10CF:10SD are as given in Figure 2.

In sample $80 \mathrm{H}$ : 10CF:10SD the images considered in 30um, 20um, 10um, 2um with $\mathrm{WD}=10.3 \mathrm{~mm}$, and magnification are the same. In the sample the images are not smooth at any magnification it has gaps on the surface when we go inner surface of the sample the surface is not finished perfectly.

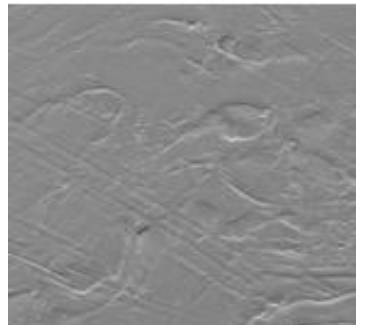

$\mathrm{EHT}=10.00 \mathrm{KV}, \mathrm{Mag}=500 \mathrm{X}$,

$\mathrm{WD}=10.2 \mathrm{~mm}$, Signal A=SE2

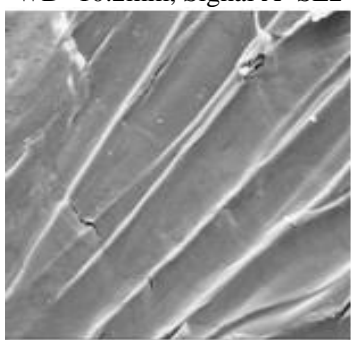

$\mathrm{EHT}=10.00 \quad \mathrm{KV}, \quad \mathrm{Mag}=2.50$ $\mathrm{KX}, \mathrm{WD}=10.0 \mathrm{~mm}$, Signal $\mathrm{A}=\mathrm{SE} 2$

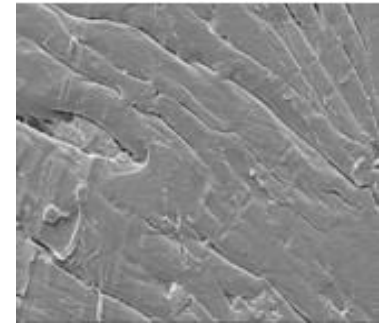

$\mathrm{EHT}=10.00 \mathrm{KV}, \mathrm{Mag}=1.00 \mathrm{KX}$ $\mathrm{WD}=10.1 \mathrm{~mm}$, Signal A=SE2

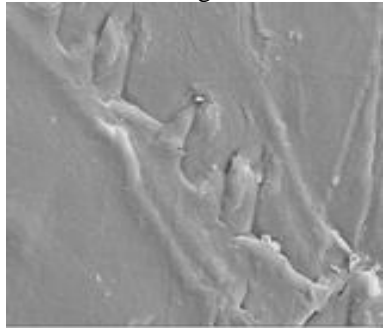

$\mathrm{EHT}=10.00 \mathrm{KV}, \mathrm{Mag}=5.00 \mathrm{KX}$, $\mathrm{WD}=10.1 \mathrm{~mm}$, Signal A=SE2

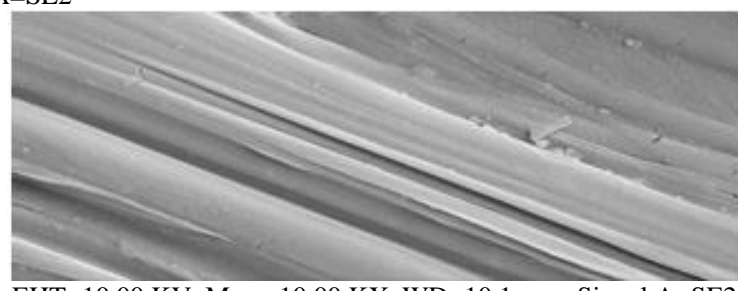

EHT=10.00 KV, Mag=10.00 KX, WD=10.1 mm, Signal A=SE2

Figure 1. The FESEM results of $80 \mathrm{H}: 15 \mathrm{CF}: 5 \mathrm{SD}$ composition with various magnifications (500 X, $1 \mathrm{KX}, 2.50$ $\mathrm{KX}, 5 \mathrm{KX}$ and $10 \mathrm{KX})$

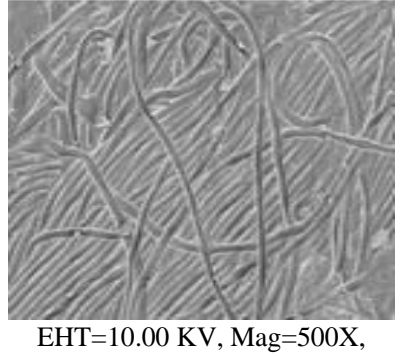

$\mathrm{WD}=10.2 \mathrm{~mm}$, Signal A=SE2

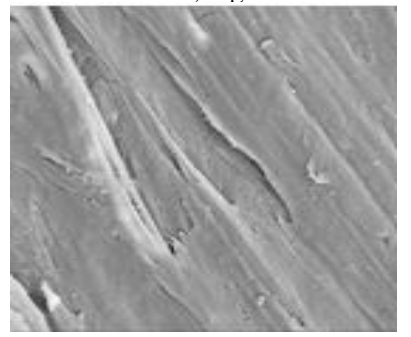

$\mathrm{EHT}=10.00 \mathrm{KV}, \mathrm{Mag}=2.50 \mathrm{KX}$ $\mathrm{WD}=10.3 \mathrm{~mm}$, Signal A=SE2

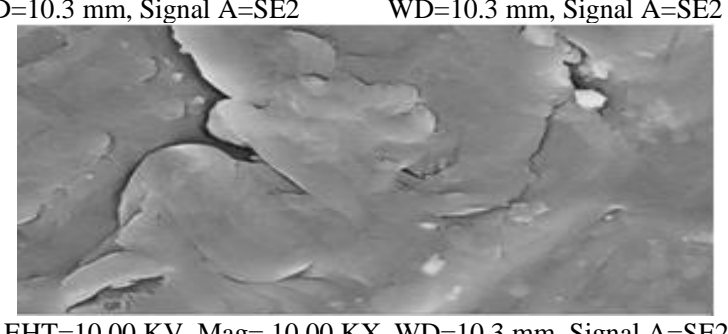

$\mathrm{EHT}=10.00 \mathrm{KV}, \mathrm{Mag}=1.00 \mathrm{KX}$ $\mathrm{WD}=10.3 \mathrm{~mm}$, Signal A=SE2

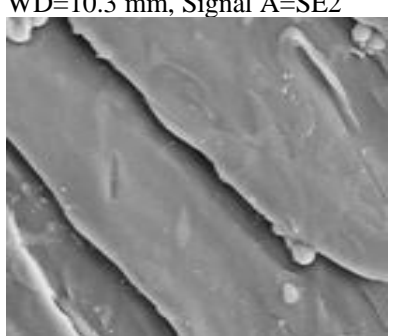

$\mathrm{EHT}=10.00 \mathrm{KV}, \mathrm{Mag}=5.00 \mathrm{KX}$, $\mathrm{DD}=10.3 \mathrm{~mm}$, Signal $\mathrm{A}=\mathrm{SE} 2$

Figure 2. The FESEM results of $80 \mathrm{H}: 10 \mathrm{CF}$ :10SD composition with various magnifications (500 X, $1 \mathrm{KX}, 2.50$ $\mathrm{KX}, 5 \mathrm{KX}$ and $10 \mathrm{KX}$ ) 
The FESEM results with composition $70 \mathrm{H}: 30 \mathrm{CF}$ are as given in Figure 3.

In sample $70 \mathrm{H}: 30 \mathrm{CF}$ the images considered in 20um, the image is like lines not a smooth surface at magnification 500X when considering $1.00 \mathrm{KX}$ mag the surface image is not perfect and the surface is not smooth at $2 \mathrm{um}$.

The FESEM results with composition $80 \mathrm{H}: 20 \mathrm{CF}$ are as given in Figure 4.

In $80 \mathrm{H}: 20 \mathrm{CF}$ the surface image is not smooth at 500x mag in $20 \mathrm{um}$ at $1.00 \mathrm{KX}$ mag the image is like wires placed on the surface at $20 \mathrm{um}$. In mag $2.50 \mathrm{kx}$ at $10 \mathrm{um}$ the surface is smooth again in $5.00 \mathrm{kx}$ at $2 \mathrm{um}$ image the surface is not filled properly, in $10.00 \mathrm{kx}$ at $1 \mathrm{um}$ the image is irregular.

The FESEM results with composition 70H:30SD are as given in Figure 5.

In 70H:30SD the mag 500x at 20um is better when compared to the above sample image at this magnification. In other magnification also the surface images are better compared with the above sample. There are little cracks in this sample and some gaps found in $10.00 \mathrm{kx}$ at $3 \mathrm{um}$.

The FESEM results with composition 80H:5CF:15SD are as given in Figure 6.

In $80 \mathrm{H}: 5 \mathrm{CF}: 15 \mathrm{SD}$ the images are very good at all magnifications compared to all the samples also because of the rachis the material has gathered at some places, if we spread those powder to all directions the image has done properly in FESEM.

It was observed from all the images of FESEM that the combination of HDPE and natural fibers like neem saw dust and chicken feather provides better surface smoothness, less irregularities and cracks.

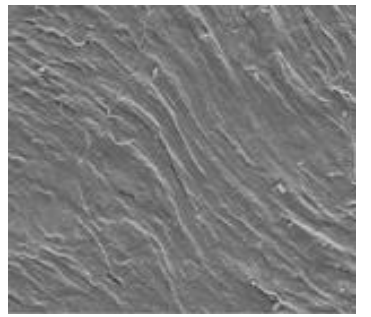

$\mathrm{EHT}=10.00 \mathrm{KV}, \mathrm{Mag}=500 \mathrm{X}$, $\mathrm{WD}=10.0 \mathrm{~mm}$, Signal A=SE2

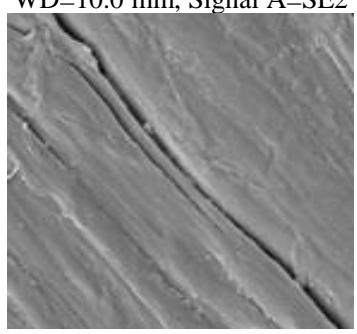

$\mathrm{EHT}=10.00 \quad \mathrm{KV}, \quad \mathrm{Mag}=2.50$ $\mathrm{KX}, \mathrm{WD}=10.0 \mathrm{~mm}$, Signal $\mathrm{A}=\mathrm{SE} 2$

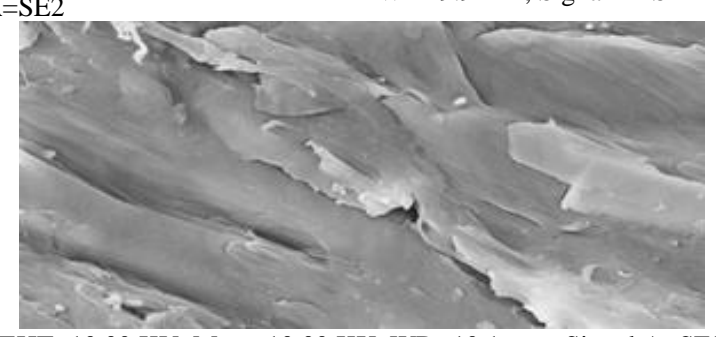

$\mathrm{EHT}=10.00 \mathrm{KV}, \mathrm{Mag}=10.00 \mathrm{KX}, \mathrm{WD}=10.1 \mathrm{~mm}$, Signal A=SE2

Figure 3. The FESEM results of 70H:30CF composition with various magnifications $(500 \mathrm{X}, 1 \mathrm{KX}, 2.50 \mathrm{KX}, 5 \mathrm{KX}$ and 10 $\mathrm{KX})$
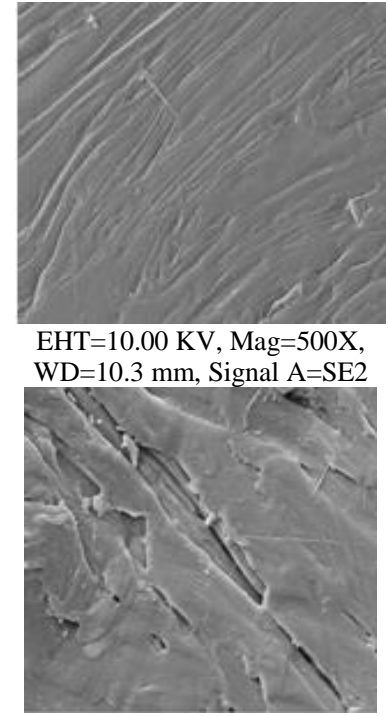

$\mathrm{EHT}=10.00 \mathrm{KV}, \mathrm{Mag}=2.50 \mathrm{KX}$ $\mathrm{WD}=10.1 \mathrm{~mm}$, Signal A=SE2

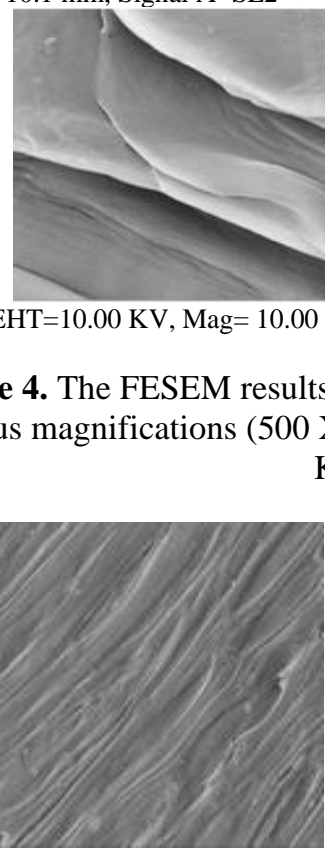

$\mathrm{EHT}=10.00 \mathrm{KV}, \mathrm{Mag}=500 \mathrm{X}$ $\mathrm{WD}=9.6 \mathrm{~mm}$, Signal A=SE2

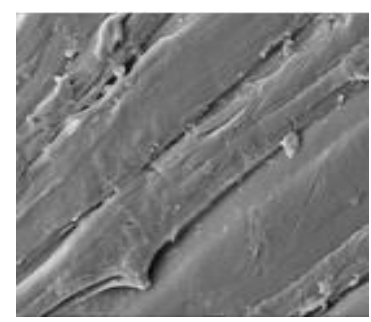

$\mathrm{EHT}=10.00 \quad \mathrm{KV}, \quad \mathrm{Mag}=2.50$ $\mathrm{KX}, \quad \mathrm{WD}=9.4 \mathrm{~mm}, \quad$ Signa $\mathrm{A}=\mathrm{SE} 2$

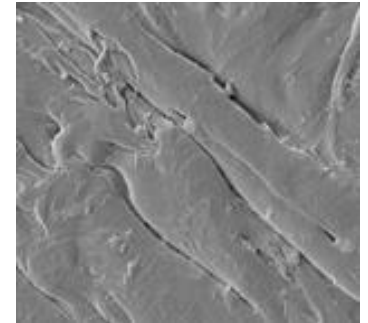

$\mathrm{EHT}=10.00 \mathrm{KV}, \mathrm{Mag}=1.00 \mathrm{KX}$

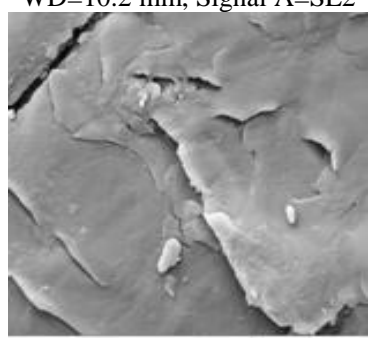

$\mathrm{EHT}=10.00 \mathrm{KV}, \mathrm{Mag}=5.00 \mathrm{KX}$, $\mathrm{WD}=9.8 \mathrm{~mm}$, Signal A=SE2 $\mathrm{WD}=10.2 \mathrm{~mm}$, Signal A=SE2

Figure 4. The FESEM results of $80 \mathrm{H}: 20 \mathrm{CF}$ composition with various magnifications $(500 \mathrm{X}, 1 \mathrm{KX}, 2.50 \mathrm{KX}, 5 \mathrm{KX}$ and 10 $\mathrm{KX})$

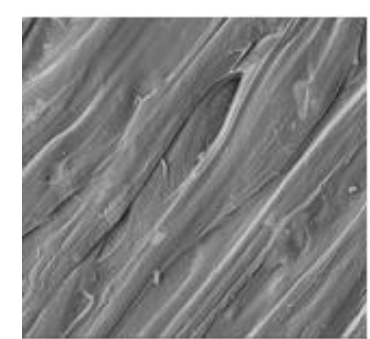

$\mathrm{EHT}=10.00 \mathrm{KV}, \quad \mathrm{Mag}=1.00$ $\mathrm{KX}, \mathrm{WD}=9.6 \mathrm{~mm}$, Signal $\mathrm{A}=\mathrm{SE} 2$

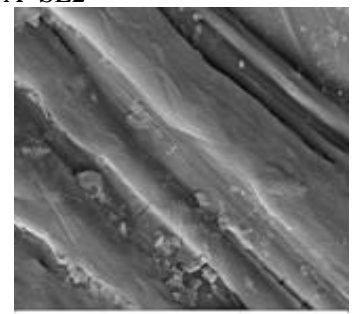

$\mathrm{EHT}=10.00 \mathrm{KV}, \quad \mathrm{Mag}=5.00$ $\mathrm{KX}, \quad \mathrm{WD}=9.3 \mathrm{~mm}$, Signal $\mathrm{A}=\mathrm{SE} 2$

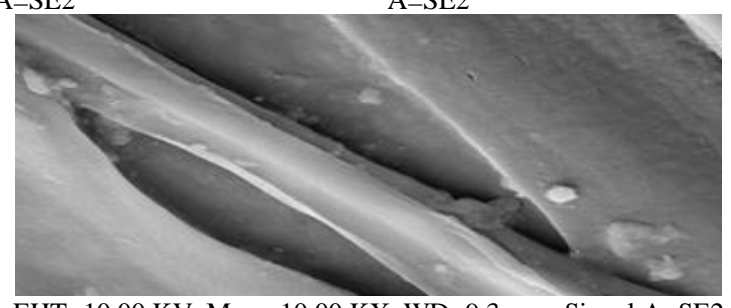

$\mathrm{EHT}=10.00 \mathrm{KV}, \mathrm{Mag}=10.00 \mathrm{KX}, \mathrm{WD}=9.3 \mathrm{~mm}$, Signal A=SE2

Figure 5. The FESEM results of 70H:30SD composition with various magnifications $(500 \mathrm{X}, 1 \mathrm{KX}, 2.50 \mathrm{KX}, 5 \mathrm{KX}$ and $10 \mathrm{KX})$ 


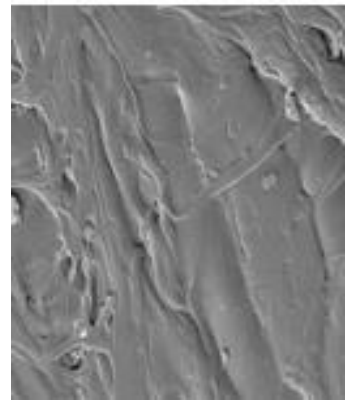

$\mathrm{EHT}=10.00 \mathrm{KV}, \mathrm{Mag}=500 \mathrm{X}$, $\mathrm{WD}=10.4 \mathrm{~mm}$, Signal A=SE2

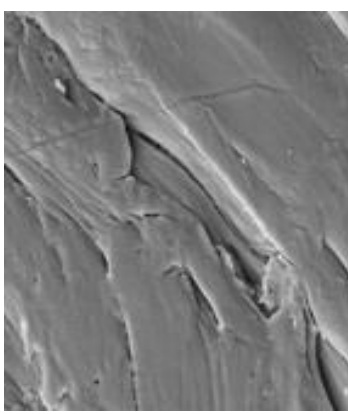

$\mathrm{EHT}=10.00 \quad \mathrm{KV}, \quad \mathrm{Mag}=2.50$ $\mathrm{KX}, \mathrm{WD}=10.4 \mathrm{~mm}$, Signal $\mathrm{A}=\mathrm{SE} 2$

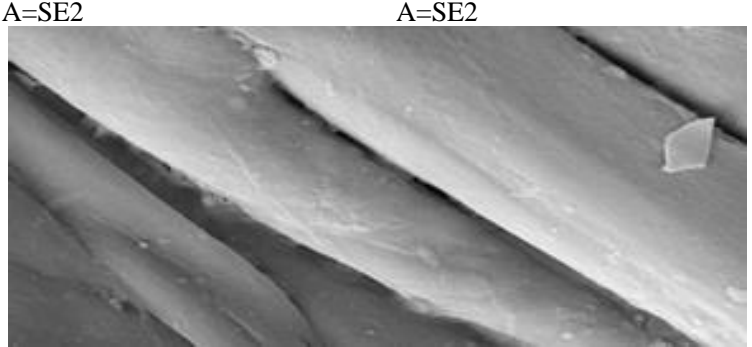

$\mathrm{EHT}=10.00 \mathrm{KV}, \mathrm{Mag}=10.00 \mathrm{KX}, \mathrm{WD}=10.4 \mathrm{~mm}$, Signal A=SE2

Figure 6. The FESEM results of $80 \mathrm{H}: 5 \mathrm{CF}: 15 \mathrm{SD}$ composition with various magnifications $(500 \mathrm{X}, 1 \mathrm{KX}, 2.50$ $\mathrm{KX}, 5 \mathrm{KX}$ and $10 \mathrm{KX})$

\subsection{EDXA results}

The EDXA results of composition 80H: 15CF:5SD (100um) is given in Figure 7. In the graph $\mathrm{C}$ represents and $\mathrm{O}$ represents carbon and oxygen.

The elemental composition of the $80 \mathrm{H}: 15 \mathrm{CF}: 5 \mathrm{SD}$ in the spectrum 300C: $100 \mathrm{C}$ is given in Table 1.

The EDXA results of composition $70 \mathrm{H}$ : $30 \mathrm{CF}$ (100um) is given in Figure 8.

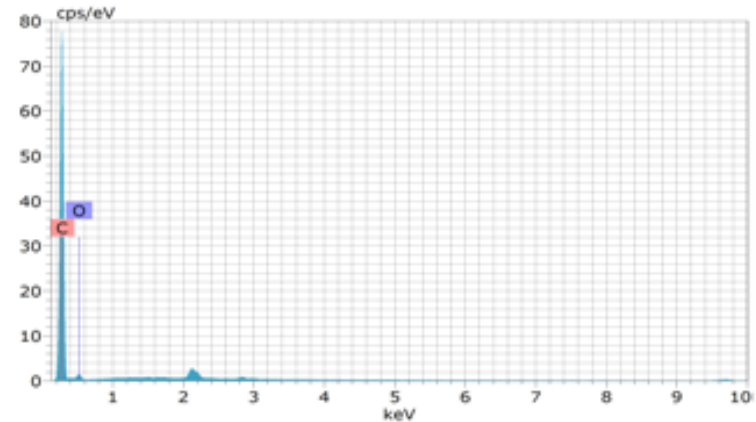

Figure 7. The EDXA results of composition $80 \mathrm{H}$ : 15CF:5SD (100um)

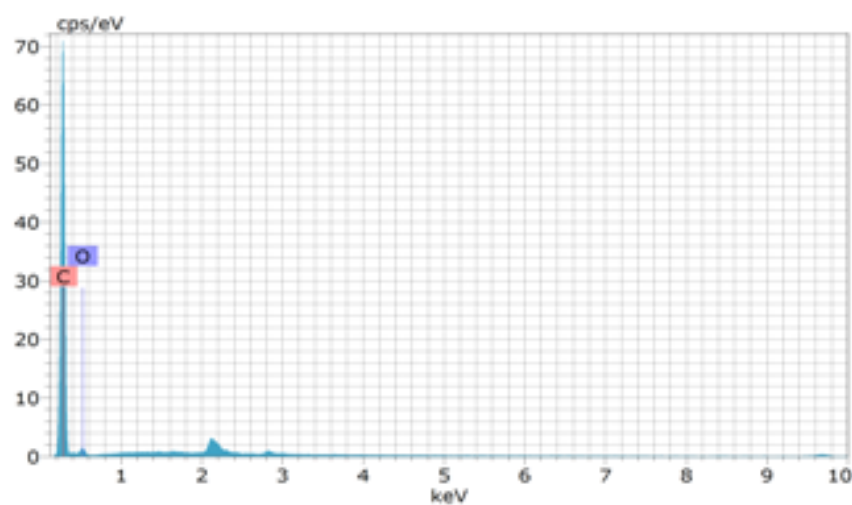

Figure 8. The EDXA results of composition $70 \mathrm{H}: 30 \mathrm{CF}$ (100um)

The EDXA results of composition $80 \mathrm{H}: 20 \mathrm{CF}$ (100um) is given in Figure 9.

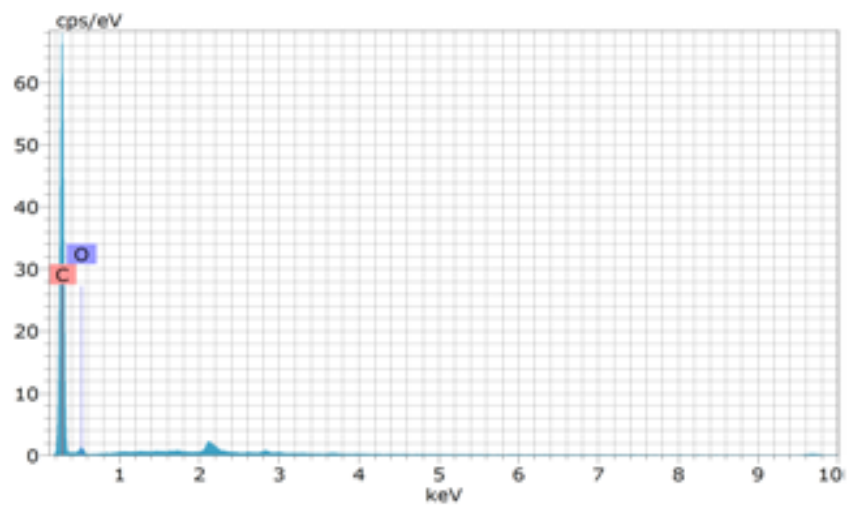

Figure 9. The EDXA results of composition $80 \mathrm{H}: 20 \mathrm{CF}$ (100um)

The elemental composition of the spectrum $80 \mathrm{H}-20 \mathrm{CF}$ is given in Table 3 .

In samples 80H:10SD:10CF, 80H:5CF:15SD, and $80 \mathrm{H}: 15 \mathrm{CF}: 5 \mathrm{SD}$ the magnification is $500 \mathrm{xkv}, 20.0 \mathrm{kv}$, WD:9.9mm and at $100 \mathrm{um}$ the elemental analysis is done. In these samples the elements are carbon and oxygen. For that Kseries, unn \% is $91.62 \%$ for $(\mathrm{C})$ and $8.38(\mathrm{O})$, norm $\%$ is $91.62 \%$ for $(\mathrm{C})$ and 8.38 for $(\mathrm{O})$, atm \% is 93.57 for $(\mathrm{C})$ and 6.43 for $(\mathrm{O})$ if we 3 sigma, $30.52(\mathrm{C})$ and $4.42(\mathrm{O})$. In sample $80 \mathrm{H}: 20 \mathrm{CF}$ also the same elements found the series and the atom, 3sigma values are changes only to +/- 0.2 values. The total is $100 \%$ only for all the sample elements. In $70 \mathrm{H}: 30 \mathrm{CF}$ also the elements found the same, the series, atoms, 3 sigma also changes in points only everything is same. In $80 \mathrm{H}: 20 \mathrm{SD}$ and $70 \mathrm{H}: 30 \mathrm{SD}$ the elements, atoms, 3 sigma is the same here also changes in + /- point only.

From this testing method elemental composition of ratios observed and it was identified in all the samples the elements are combinations of carbon and the oxygen.

XRD Results:

The XRD results for all samples are as given below. The XRD result of the composition $80 \mathrm{H}-10 \mathrm{CF}-10 \mathrm{SD}$ is given in Figure 10.

The elemental composition of the spectrum $70 \mathrm{H}-30 \mathrm{CF}$ is given in Table 2. 
Table 1. Elemental composition of the Spectrum: 300C:100C

\begin{tabular}{cccccc}
\hline Element (wt. \%) & Series (wt.\%) & Unn (at. \%) & C Norm (wt.\%) & C Atom & C Error (3 Sigma) \\
\hline Carbon & K-Series & 91.62 & 91.62 & 93.57 & 30.52 \\
Oxygen & K-Series & 8.38 & 8.38 & 6.43 & 4.42 \\
\hline Total: $100.00 \quad 100.00$ & 100.00 & & & &
\end{tabular}

Table 2. Elemental composition of the Spectrum: $70 \mathrm{H}-30 \mathrm{CF}$

\begin{tabular}{cccccc}
\hline Element (wt.\%) & Series (wt.\%) & Unn (at. \%) & C Norm (wt.\%) & C Atom & C Error (3 Sigma) \\
\hline Carbon & K-Series & 91.02 & 91.02 & 93.10 & 30.43 \\
Oxygen & K-Series & 8.98 & 8.98 & 6.90 & 4.72 \\
\hline
\end{tabular}

Total: $100.00 \quad 100.00 \quad 100.00$

Table 3. Elemental composition of the Spectrum: $80 \mathrm{H}-20 \mathrm{CF}$

\begin{tabular}{cccccc}
\hline Element (wt. \%) & Series (wt.\%) & Unn (at. \%) & C Norm (wt.\%) & C Atom & C Error (3 Sigma) \\
\hline Carbon & K-Series & 91.47 & 91.47 & 93.46 & 30.50 \\
Oxygen & K-Series & 8.53 & 8.53 & 6.54 & 4.50 \\
\hline
\end{tabular}

Total: $100.00 \quad 100.00 \quad 100.00$

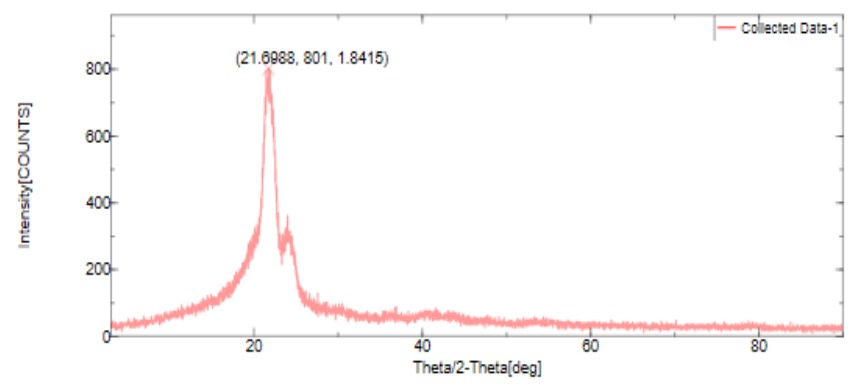

Figure 10. The XRD result of composition 80H-10CF-10SD

The XRD result of the composition $80 \mathrm{H}-5 \mathrm{CF}-15 \mathrm{SD}$ is given in Figure 11.

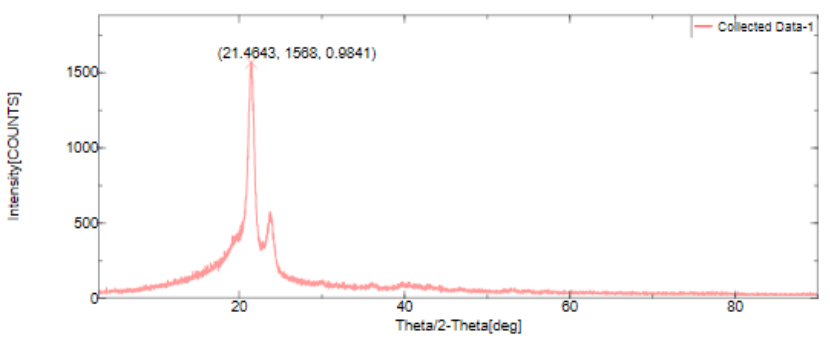

Figure 11. XRD result of the composition $80 \mathrm{H}-5 \mathrm{CF}-15 \mathrm{SD}$

The XRD result of the composition $80 \mathrm{H}-15 \mathrm{CF}-5 \mathrm{SD}$ is given in Figure 12.

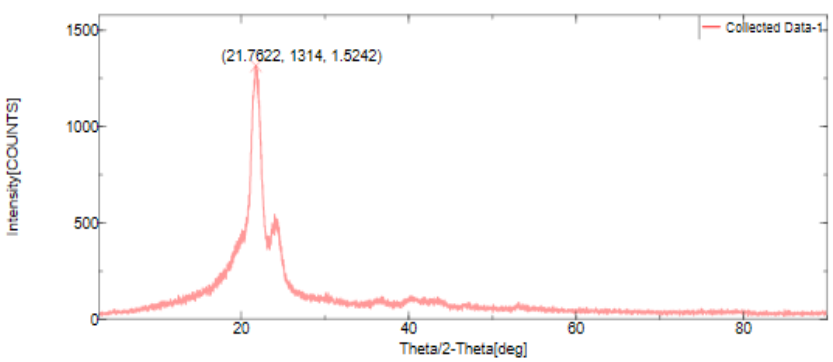

Figure 12. XRD result of the composition $80 \mathrm{H}-15 \mathrm{CF}-5 \mathrm{SD}$

The XRD result of the composition $80 \mathrm{H}-20 \mathrm{CF}$ is given in Figure 13.

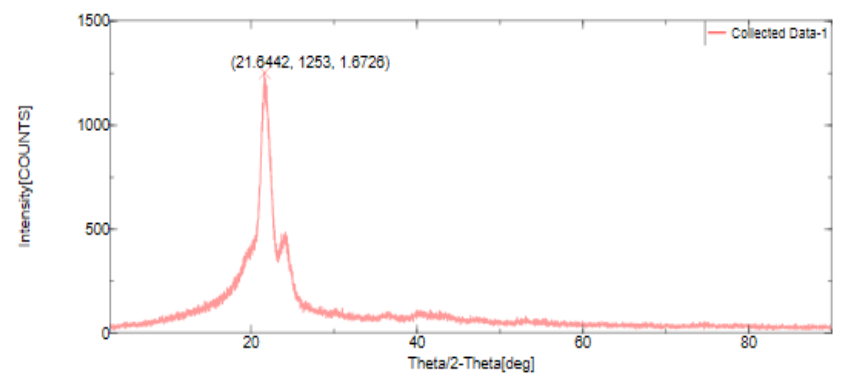

Figure 13. XRD result of the composition $80 \mathrm{H}-20 \mathrm{CF}$

The XRD result of the composition $70 \mathrm{H}-30 \mathrm{CF}$ is given in Figure 14.

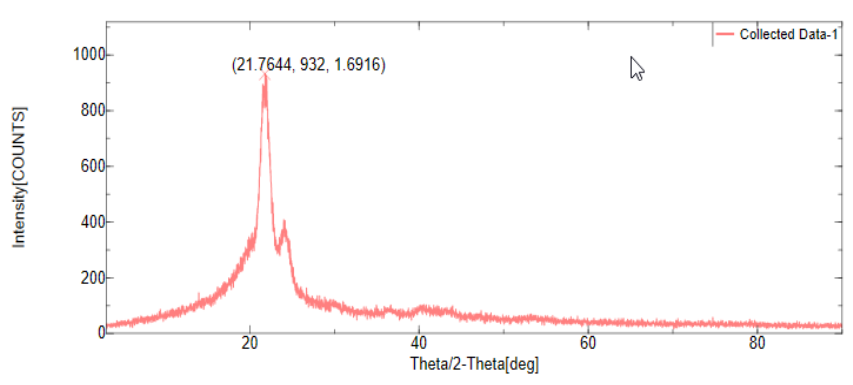

Figure 14. XRD result of the composition $70 \mathrm{H}-30 \mathrm{CF}$

The XRD result of the composition $70 \mathrm{H}-30 \mathrm{SD}$ is given in Figure 15.

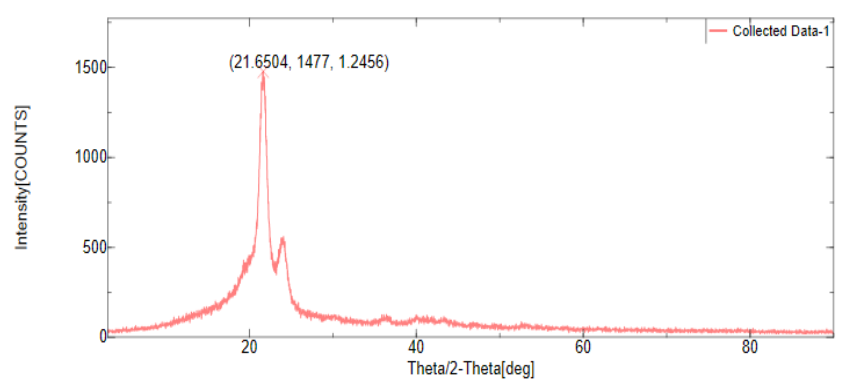

Figure 15. XRD result of the composition 70H-30SD 


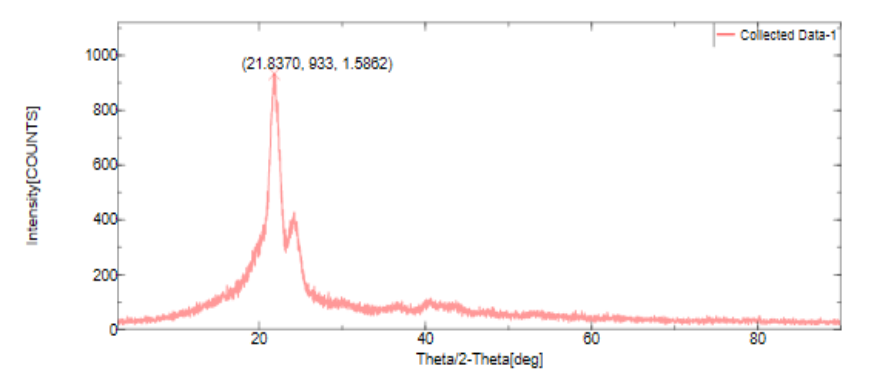

Figure 16. XRD result of the composition $80 \mathrm{H}: 20 \mathrm{SD}$

The XRD result of the composition 70H-30SD is given in Figure 16.

In the sample $80 \mathrm{H}: 10 \mathrm{CF}: 10 \mathrm{SD}$, intensity of the peak is 21.6988. The peak intensity of the sample $80 \mathrm{H}: 5 \mathrm{CF}: 15 \mathrm{SD}$, is 21.4643. In the sample $80 \mathrm{H}: 15 \mathrm{CF}: 5 \mathrm{SD}$, the peak intensity was $21.7622,1314$. The peak intensity of the $80 \mathrm{H}: 20 \mathrm{CF}$ sample is 21.6442. In the sample $70 \mathrm{H}: 30 \mathrm{CF}$ the peak intensity is 21.7644. In sample $70 \mathrm{H}: 30 \mathrm{SD}$ the peak intensity is $21.6504,1477$. The peak intensity of the sample $80 \mathrm{H}: 20 \mathrm{SD}$ is 21.8370. It was finally concluded that the intensity in all the samples is approximately same and it will be around $21+/-$ 0.84 .

\section{CONCLUSION}

It has been proved that the newly introduced composite material is more flexible and stronger when compared to individual materials. In FESEM images it was observed that it has less irregularity in the surface and no cracks observed. From the EDXA testing method the elemental composition of ratios observed and it was identified in all the samples the elements are carbon and oxygen. In XRD testing the intensity of the individual materials is around $19+/-0.6$ whereas the intensity of seven ratios are around the $21+/-0.84$. It was clear from XRD testing that the intensity of all ratios is good compared to the individual samples.

\section{REFERENCES}

[1] Najafi, S.K. (2013). Use of recycled plastics in woodplastic composites-A review. Waste Management, 33(9): 1898-1905. https://doi.org/10.1016/j.wasman.2013.05.017

[2] Gayatri, U., Srinivasarao, G., Ramakrishna, M. (2018). Development and characterization of chicken feather rachis, sawdust and HDPE hybrid composite material. Revue des Composites et des Matériaux Avancés, 28(4): 509-528. https://doi.org/10.3166/RCMA.28.509-528

[3] Alashwal, B.Y., Gupta, A., Husain, M.S.B. (2019). Characterization of dehydrated keratin protein extracted from chicken feather. IOP Conf. Series: Materials Science and Engineering, Kuantan, Pahang, Malaysia, 702: $\quad 012033 . \quad$ https://doi.org/10.1088/1757899X/702/1/012033

[4] Kuciel, S., Bazan, P., Liber-Kneć, A., Gądek-Moszczak, A. (2019). Physico-mechanical properties of the poly(oxymethylene) composites reinforced with glass fibers under dynamical loading. Polymers, 11(12): 2064. https://doi.org/10.3390/polym11122064

[5] Adekomaya, O., Adediran, A.A., Adama, K.O. (2018).
Characterization and morphological properties of glass fiber reinforced epoxy composites fabricated under varying degrees of hand lay-up techniques. Journal of Applied Sciences and Environmental Management, 22(1): 110. https://doi.org/10.4314/jasem.v22i1.20

[6] Boussehel, H., Mazouzi, D.E., Belghar, N., Guerira, B., Lachi, M. (2019). Effect of chemicals treatments on the morphological, mechanical, thermal and water uptake properties of polyvinyl chloride/ palm fibers composites. Revue des Composites et des Matériaux Avancés, 29(1): 1-8. https://doi.org/10.18280/rcma.290101

[7] Montealegre-Meléndez, I., Arévalo, C., Pérez-Soriano, E.M. (2018). Microstructural and XRD analysis and study of the properties of the system Ti-TiAl-B4C processed under different operational conditions. Metals, 8(367): 1-16. https://doi.org/10.3390/met8050367

[8] Volkova, V.K., Kalistratova, L.F. (2015). X-ray diffraction analysis of structure of composite materials based on polytetrafluoroethylene during thermal exposure. Inorganic Materials: Applied Research, 6(4): 411-413. https://doi.org/10.1134/S2075113315040255

[9] Ma, B.M., Qiao, X., Hou, X.L., Yang, Y.Q. (2016). Pure keratin membrane and fibers from chicken feather. International Journal of Biological Macromolecules, 89: 614-621. https://doi.org/10.1016/j.ijbiomac.2016.04.039

[10] Mirjalili, B.B.F., Bamoniri, A., Nazemian, S., Reshquiyea, R.Z. (2019). $\mathrm{SnCl}_{4} / \mathrm{Nano}$ Sawdust as an efficient bio-based catalyst for the synthesis of 2substituted benzimidazoles and benzothiazoles. J Nanostruct, $\quad 9(1)$ : 183-189. https://doi.org/10.22052/JNS.2019.01.020

[11] Habibi, N. (2014). Preparation of biocompatible magnetite-carboxymethyl cellulose nanocomposite: Characterization of nanocomposite by FTIR, XRD, FESEM and TEM. Spectrochimica Acta Part A: Molecular and Biomolecular Spectroscopy, 131: 55-58. https://doi.org/10.1016/j.saa.2014.04.039

[12] Ang, B.C., Yaacob, I.I., Nurdin, I. (2013). Investigation of $\mathrm{Fe}_{2} \mathrm{O}_{3} / \mathrm{SiO}_{2}$ Nanocomposite by FESEM and TEM. Journal of Nanomaterials, 2013: 1-6. https://doi.org/10.1155/2013/980390

[13] Islam, M.N., Islam, M.S. (2013). Characterization of chemically modified sawdust-reinforced recycled polyethylene Composites. Journal of Thermoplastic Composite Materials, 28(8): 1135-1153. https://doi.org/10.1177/0892705713503671

[14] Chen, X.J., Wu, S.F., Yi, M.H., Ge, J.F., Yin, G.Q., Li, X.M. (2018). Preparation and physicochemical properties of blend films of feather keratin and poly(vinyl alcohol) compatibilized by tris(hydroxymethyl)aminomethane. Polymers, 10(10): 1054. https://doi.org/10.3390/polym10101054

[15] Oladele, I.O., Okoro, A.M., Omotoyinbo, J.A., Khoathane, M.C. (2018). Evaluation of the mechanical properties of chemically modified chicken feather fibres reinforced high density polyethylene composites. Journal of Taibah University for Science, 12(1): 56-63. https://doi.org/10.1080/16583655.2018.1451103

[16] Najafi, S.K., Hamidinia, E., Tajvidi, M. (2006). Mechanical properties of composites from sawdust and recycled plastics. Journal of Applied Polymer Science, 100: 3641-3645. https://doi.org/10.1002/app.23159

[17] Gayatri, U., Srinivasarao, G., Ramakrishna, M. (2020). Mechanical and thermal characterization of chicken 
raches/sawdust reinforced HDPE hybrid composites. International Journal of Mechanical and Production Engineering Research and Development, 10(1): 327-344. https://doi.org/10.24247/ijmperdfeb202028

[18] Ghani, S.A., Tan, S.J., Yeng, T.S. (2014). Properties of chicken feather fiber-filled low-density polyethylene composites: The effect of polyethylene grafted maleic anhydride. Polymer-Plastics Technology and Engineering, 52(5): 495-500. https://doi.org/10.1080/03602559.2012.762018
[19] Supri, A.G., Aizat, A.E., Yazid, M., Masturina, M. (2015). Chicken feather fibers-recycled high-density polyethylene composites: The effect of $\varepsilon$-caprolactam. Journal of Thermoplastic Composite Materials, 28(3): 327-339. https://doi.org/10.1177/0892705713484746

[20] Habibi, M., Najafi, S.K., Ghasemi, I. (2017). Rheological and mechanical properties of composites made from wood flour and recycled LDPE/HDPE blend. Iranian Polymer Journal, 26(12): 949-956. 